\title{
Cesarean section in spinal anesthesia on a patient with mesencephalic tumor and ventriculoperitoneal drainage -A case report-
}

\author{
Ivana Hirs, and Patricia Grbcic \\ Department of Anesthesiology, Reanimation and Inetsive Care, General Hospital Varazdin, Varazdin, Croatia
}

A seventeen-year-old pregnant woman with a mesencephalic tumor and ventriculoperitoneal (VP) drainage was admitted to the hospital at full term pregnancy to give birth. Elective cesarean section was performed because of her prime disease (mesencephalic tumor), breech position of the baby, gestational diabetes and expected weight of the baby of more than $4 \mathrm{~kg}$. The operation was performed under spinal anesthesia. Spinal block was performed smoothly, using a pencil point spinal needle $27 \mathrm{G}$, at the L3-L4 intervertebral space, with hyperbaric bupivacaine $8 \mathrm{mg}$ plus fentanyl $15 \mu \mathrm{g}$. Sensory block Th 5 was reached within 5 minutes. The patient was hemodynamically stabile during the anesthesia and the procedure was uneventful. The woman developed no neurologic symptoms, and a healthy female child was born. This is the first case of a pregnant woman with a cerebral tumor and VP drainage on whom a successful delivery was performed with C-section under spinal anesthesia. (Korean J Anesthesiol 2012; 63: 263-265)

Key Words: Anesthesia spinal, Brain stem neoplasms, Cesarean section, Ventriculoperitonel shunt.

Until the 1960's, hydrocephalus had a poor prognosis, but since silicon Cerebrospinal fluid (CSF) shunts were put into use later in that decade, there was a dramatic increase of survival rate. Until 1988, there had been only 13 mentioned cases of pregnancy in patients with CSF shunts [1]. Today, it is presumed that ventriculoperitoneal (VP) drainage in a pregnant patient with hydrocephalus, if it works properly, does not affect the method of delivery (vaginal labor or caesarean section). These patients are also appropriate for epidural or spinal analgesia/ anesthesia, although caution would need to be taken [2].
Cerebral tumors are rare in pregnancy; they usually appear as an urgent condition when the patient signalizes headache, seizures and motoric or visual disturbances. If the pregnancy can be carried through to term, then the cesarean section (C-section) is performed, mostly under general anesthesia. In some cases, during this procedure, the brain tumor is also operated.

We present a case of elective C-section in spinal anesthesia at primigravida with VP drainage and mesencephalic tumor.

Received: July 25, 2011. Revised: October 18, 2011. Accepted: November 11, 2011.

Corresponding author: Ivana Hirs, M.D., Department of Anesthesiology, Reanimation and Inetsive Care, General Hospital Varazdin, I. Mestrovica bb, Varazdin 42000, Croatia. Tel: 385-42-393-091, Fax: 385-42-393-096, E-mail: ivana.hirs@gmail.com

두 This is an open-access article distributed under the terms of the Creative Commons Attribution Non-Commercial License (http:// creativecommons.org/licenses/by-nc/3.0/), which permits unrestricted non-commercial use, distribution, and reproduction in any medium, provided the original work is properly cited. 


\section{Case Report}

A seventeen-year-old pregnant woman with a mesencephalic tumor and VP drainage was admitted to the Obstetric Department to be prepared for elective C-section. Anamnestically, and from the available medical data, we discovered that the patient had the mesencephalon tumor since her 9th year. During her childhood, VP drainage was implanted, because of the brain tumor, and an attempt of a stereotactic biopsy was performed. The stereotactic biopsy was unsuccessful and was not repeated due to the improvement of the patient's medical condition and the lack of evidence that the illness was progressing. Since then, the patient has been under regular annual neurosurgical control. On the most recent Magnet Resonance imaging (MR), performed one month before her pregnancy, the dimensions of the tumor were: axial $27.7 \times 27.2$ $\mathrm{mm}$, coronal $28.9 \times 19.8$, sagittal $27.1 \times 23.2 \mathrm{~mm}$ (Fig. 1). Eight obstetric examinations were performed during pregnancy, but no neurosurgical control was performed. We assume that VP drainage worked well because the patient had no symptoms of increased intracranial pressure. There were some complications during the pregnancy. In the $27^{\text {th }}$ week there was a urinaryinfection that was treated with antibiotics, and the patient also developed gestational diabetes.

The patient was scheduled for elective C-section because of her prime disease (mesencephalic tumor), breech position of the baby, gestational diabetes and expected weight of the baby of more than $4 \mathrm{~kg}$. Under the assumption that the VP drainage worked well, we decided to perform the operation under spinal anesthesia because of expected difficult airway management.

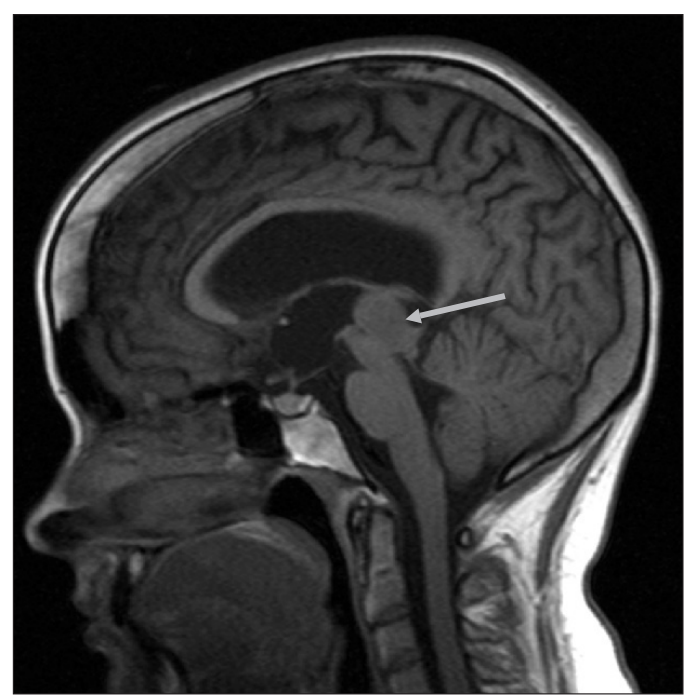

Fig. 1. Brain MR of patient one month before pregnancy. Dimensions of tumor are axial $27.7 \times 27.2 \mathrm{~mm}$, coronal $28.9 \times 19.8$, sagittal $27.1 \times$ $23.2 \mathrm{~mm}$.
The patient had a Mallampati score IV, edematous soft tissue of the face and mouth and a high Body mass index (BMI) 38.

Coagulation parameters were good: prothrombin time 10 s, platelets count $386 \times 10^{9} / \mathrm{L}$, and blood pressure was $150 / 100$ mmHg. The patient signed the informed consent and was prepared for a regional anesthesia with intravenous prehydration. Spinal block was performed with a pencil point spinal needle $27 \mathrm{G}$, at the L3-L4 intervertebral space, with hyperbaric bupivacaine $8 \mathrm{mg}$ plus fentanyl $15 \mu \mathrm{g}$.

The patient's height was $157 \mathrm{~cm}$ and her weight was $95 \mathrm{~kg}$. We used the manufacturer's dose recommendation (from 10$20 \mathrm{mg}$ ), though with a reduction because of the substitution of fentanyl. Sensory block Th 5 was reached within 5 minutes. The patient was hemodynamically stabile during the anesthesia, systolic blood pressure was between 120 and $150 \mathrm{mmHg}$, pulse was $80-120 / \mathrm{min}$, and oxygen saturation was $100 \%$. The operative procedure was uneventful; a female child was born, weighing 4,050 g, and $50 \mathrm{~cm}$ in length. The Apgar score in the first and fifth minute was $10 / 10$. The postoperative period was also uneventful, so the mother and child were discharged from the hospital on the $8^{\text {th }}$ day after birth.

\section{Discussion}

While referring to the past literature, we found a series of case reports about newly detected hydrocephalus or brain tumor during pregnancy [3-8]. Today, it is presumed that VP drainage on a pregnant patient with hydrocephalus does not affect the mode of labor: vaginal or caesarean section. C-section should be reserved only for patients with a malfunction of the shunt or with obstetric indications. Epidural or spinal analgesia and anesthesia are also allowed, but a certain amount of attention must be given [2]. Increased intra-abdominal pressure during the pregnancy can lead to disturbance of liquor drainage and eventually result in a malfunction of the shunt. According to Wisoff et al. [3], 59\% of such patients have an increase of intracranial pressure. During the pregnancy, there is an increase of the amount of liquor content and venous distension, which compromises compliance and leads to symptoms of increased intracranial pressure [9]. The risk of VP drainage malfunction is minimal because the valve is unidirectional and intra-abdominal pressure during labor is only intermittently increased [9].

The approach taken with pregnant patients with a cerebral tumor should be multidisciplinary, involving a neurosurgeon, obstetrician, neonatologist and anesthesiologist. Individual case management is advised according to the surgical and neuroanesthetic requirements and to the gestational age.

Therapeutic options include $[7,10,11]$ :

1) Neurosurgery performed while maintaining fetus in utero 
in early pregnancy

2) C-section before neurosurgical operation

3) C- section followed by neurosurgical operation

There are no general recommendations for delivery with these patients so the decision lies on the recommendation of the neurosurgeon for each patient. Although there are some mentioned cases of vaginal delivery, most of the patients with a brain tumor are scheduled for C-section.

Pregnancy itself causes hormonal imbalance with fluid retention, a more turbulent response to stress, and some repercussions to the central nervous system (CNS). A brain tumor causes shifting of neurovascular structures and the surrounding oedema. In combination with pregnancy, especially during the vaginal (natural) delivery where a rise in intracranial pressure is present, there is a greater risk of fatal complications such as brain incarceration or haemorrhage of the tumor. Anesthesia for patients with a brain tumor must be treated very delicately and the anesthesiologist must decide whether to use general or regional anesthesia. Each type of delivery bears its own risks. General anesthesia comes with the danger of aspiration and an insufficient depth of anesthesia can cause a rise in intracranial pressure (ICP). Regional anesthesia, e.g. spinal anesthesia, can cause loss of liquor and brain incarceration. Regional anesthesia may be appropriate when delivery is performed subsequent to successful and uncomplicated neurosurgery. The woman should be alert, cooperative, and preferably have normal ICP. This approach reduces the risk of life threatening induced morbidity and mortality [11]. Also, while most of the anesthesiologists chose general anesthesia for C-section $[5,10]$, nowadays there are several case reports of regional anesthesia for patients with brain tumors [12-14].

With our patient, we were confronted with a double challenge; mesencephalic tumor and VP drainage. We found ourselves with the dilemma of which type of anesthesia to chose. Since the patient had no symptoms of her prime disease during the pregnancy, and no signs of raised ICP, we treated her as capable for regional (spinal) anesthesia.

The patient's medical records reassured us that her brain tumor was stationary and the functionality of the VP drainage was evaluated on the grounds of lack of symptoms for raised ICP.

According to the available literature, this is the first case of a pregnant woman with cerebral tumor and VP drainage who underwent successful delivery with C-section under spinal anesthesia.

From our experience and referring to the past literature the following conclusions were drawn:

- VP drainage in a pregnant patient with hydrocephalus does not affect the mode of labor: vaginal or caesarean section
- Epidural or spinal analgesia and anesthesia are also allowed in patients with VP drainage

- Delivery method for patients with brain tumors and/or VP drainage should be determined by consensus between the obstetrician and neurosurgeon

- Regional anesthesia is safe for patients who have a brain tumor and implanted VP-drainage that works properly

\section{References}

1. Samuels P, Driscoll DA, Landon MB, Ludmir J, McKrisky PJ, Mennuti MT, et al. Cerebrospinal fluid shunts in pregnancy. Report of two cases and review of literature. Am J Perinatol 1988; 5: 22-5.

2. Haeussler B, Laimer E, Putz G, Marth C, Haeussler R. Pregnancy, delivery and postpartum care of women with ventriculo-peritonel shunted hydrocephalus; a case of series. Internet J Gynaecol Obstet [Serial on internet]. $2010 \mathrm{Apr}$ [2010 Apr 4]. Available from: http:// www.ispub.com/journal/the_internet_journal_of_gynecology_ and_obstetrics/volume_12_number_2_3/article/pregnancydelivery-and-postpartum-care-of-women-with-ventriculoperitoneal-shunted-hydrocephalus-a-case-series.html.

3. Wisoff JH, Kratzert KJ, Handwerker SM, Young BK, Epstein F. Pregnancy in patient with cerebrospinal fluid shunt: report of series and rewiew of the literature. Neurosurgery 1991; 29: 827-31.

4. Nikolov A, Surchev Zh, Nalbanski B, Diavolov V, Dimitrov A. Pregnancy and delivery in women with cerebrospinal fluid shunt due to hydrocephalus. Akush Ginekol (Sofiia) 2008; 47: 3-10.

5. Landwehr JB Jr, Isada NB, Pryde PG, Johnson MP, Evans MI, Canady AI. Maternal neurosurgical shunt and pregnancy outcome. Obstet Gynecol 1994; 83: 134-7.

6. Stevens E. Pregnancy in women with cerebrospinal shunts: a literature review and case report. J Perinatol 1996; 16: 374-80.

7. Nishio S, Morioka T, Suzuki S, Takeshita I, Ikazaki K, Fukui M, et al. Primary brain tumors manifesting during pregnancy: presentation of 6 cases and review of literature. J Clin Neurosci 1996; 3: 334-7.

8. Mackenzie AP, Levine G, Garry D, Figueroa R. Glioblastoma multiforme in pregnancy. J Matern Fetal Neonatal Med 2005; 17: 81-3.

9. Ryken TC. Idiopatic intracranial hypertension (Pseudotumor cerebri), Hydrocephalus, and Ventriculoperitoneal shunts in pregnancy. In: Neurosurgical aspects of pregnancy. Edited by Loftus CM: Illinois, AANS. 1996, pp 165-77.

10. Chang L, Looi-Lyons L, Bartosik L, Tindal S. Anesthesia for cesarean section in two patients with brain tumors. Can J Anaesth 1999; 46: 61-5.

11. Wang LP, Paech MJ. Neuroanesthesia for the pregnant women. Anesth Analg 2008; 107: 193-200.

12. Shigeki S, Ryoichi O, Shin'ichi N, Chiemi N, Tatsuya Y, Junzo T. Anesthetic management for elective cesarean section in partuient with a coexisting brain tumor. J Clin Anesth 2003; 27: 1645-6.

13. Atanassoff PG, Alon E, Weiss BM, Lauper U. Spinal anaesthesia for caesarean section in a patient with brain neoplasma. Can J Anaesth 1994; 41: 163-4.

14. Chhabra A, Kumar N, Kumar A, Singh N, Sharma BS. Combined spinal epidural anesthesia for cesarean section in a pregnant patient with rare intracranial neoplasm. Middle East J Anesthesiol 2010; 20: 581-4. 